\title{
Santa María Magdalena: de la hagiografía al roman
}

\section{Saint Mary Magdalen: from hagiography to roman}

\author{
Wendy Morales Prado \\ El Colegio de México
}

Este trabajo compara dos versiones de la historia de santa María Magdalena para indagar la manera en que algunos componentes de la ficción novelesca empiezan a manifestarse en un discurso de tipo hagiográfico. La primera biografía está dentro de la antología de Santiago de la Vorágine que conforma La leyenda dorada. Este volumen representa la versión hagiográfica canónica, autorizada y consolidada hacia el siglo XIII en España; el segundo texto que se compara es la vida de la misma santa que aparece como la primera historia del Manuscrito escurialense h-I-13.

Palabras Clave: hagiografía, roman, ficción, cambios, mujer

This work compares two versions of the history of Mary Magdalene in order to inquire how some components of the novelistic fiction begin to appear in the hagiographic discourse. The first biography appears in an anthology by Santiago de la Voragine, titled La leyenda dorada. This book represents the hagiographic, canonical and authorized version, consolidated by the XIII century in Spain; the second text that is going to be compared, recounts the life of the very same female saint which appears as the first history of the Manuscrito Escurialense h-I-13.

KEYwORDs: hagiography, roman, fiction, changes, female

$\mathrm{E}$ n el siglo XIII de la Edad Media se pueden apreciar cambios incipientes pero definitivos en los géneros discursivos más autorizados y destacados por la tradición, como el discurso hagiográfico o vidas de santos, que gozó de bastante reputación en aquella época. Estos cambios que apuntan hacia el desarrollo del roman tienen la finalidad de acercarse a la realidad vivida por sus lectores, a sus esperanzas y a sus modos de interpretar la realidad a través de su sistema de creencias. En la Edad Media la hagiografía fue un género que nutrió el desarrollo de la incipiente novela occidental $y$, como se podrá apreciar más adelante, la hagiografía poco a poco dio paso a otro tipo de configuración discursiva, más mundana y cercana a sus lectores. 
Precisamente, el siglo XIII se destaca como un periodo significativo en cuanto a la apertura y la variación del género de vidas de santos:

La difusión del género hagiográfico encuentra una nueva vertiente en el siglo XIII, en que se consolidan las lenguas vernáculas como vehículo de textos hagiográficos, y no solo en traducciones de colecciones enteras, sino en la recreación de antiguas historias hagiográficas o composición de nuevas. A partir de aquí coexisten dos vertientes: una culta y restringida (la de la tradición latina) y otra más accesible y divulgativa (en las incipientes literaturas románicas) (Baños Vallejo, La hagiografía como género, 103).

Estas variaciones evidencian la necesidad de desarrollar una diversidad de estrategias para lograr una difusión exitosa de conductas entre los lectores. Como ejemplo de ello este trabajo compara dos versiones de la historia de santa María Magdalena para indagar la manera en que algunos componentes de la ficción novelesca empiezan a manifestarse en un discurso de tipo hagiográfico. La primera biografía está dentro de la antología de Santiago de la Vorágine que conforma La leyenda dorada, este volumen es conocido como la culminación del género de vidas de santos y representa la versión hagiográfica canónica, autorizada y consolidada hacia el siglo XIII en España; el segundo texto es la vida de la misma santa que aparece como la primera historia del Manuscrito escurialense h-I-13. Hay que señalar que esta segunda versión de santa María Magdalena está incompleta, pues en dicho documento no se conservan las páginas que permitan conocer el desenlace de la historia que nos ocupa. No obstante, a pesar de esta carencia, es posible encontrar alteraciones significativas en los dos relatos de la vida de santa María Magdalena que apuntan hacia un tratamiento y finalidades distintos de la hagiografía tradicional.

Este análisis se limita a contrastar la manera de presentar, articular, aumentar o suprimir los hechos coincidentes en los dos textos base, por lo tanto, la estructura que comparten ambos escritos se dividió en seis secuencias narrativas; cada una de ellas se detalla y comenta por separado para dar cuenta de las alteraciones que el texto del Manuscrito escurialense h-I-13 añade a la historia de La leyenda dorada. Desde luego, se señalan las repercusiones que tienen esos cambios incipientes en su paso a la ficción novelesca.

La hagiografía medieval fue un importante género literario conformado por textos "que poseen un carácter religioso y apuntan hacia un fin de edificación, [comprenden] desde documentos oficiales hasta composiciones poéticas frecuentemente desligadas de los datos históricos" (Hippolite Delehaye, apud Baños Vallejo, La hagiografía como género, 28). Esta definición, 
aunque es demasiado amplia, da cuenta de la variedad y heterogeneidad de un género que básicamente comprende el relato de la vida de un personaje cuya secuencia esencial sigue una estructura vital que manifiesta en primer lugar un "deseo de santidad",' seguido del desarrollo del necesario "proceso de perfeccionamiento" que finalmente se consolida en el "éxito: santidad probada" mediante lo sobrenatural "prodigios in vita", la "muerte", siempre serena y piadosa y una serie de "prodigios post mortem" que promueven la devoción religiosa por ese santo en particular. Esta secuencia básica que se mencionó no excluye la posibilidad de desarrollar secuencias cada vez más complejas. Las vidas de santos poseían un alto valor ejemplarizante de hondas repercusiones en la vida social:

Expresado de un modo muy simple, la función social de la hagiografía podría entenderse así: el cristiano medieval tendría aprendidas unas reglas básicas de comportamiento, las leyes de Dios y las normas de la Iglesia. Ahora bien, esos cauces de conducta causarán mayor impacto y atracción sobre los fieles si en lugar de presentarse como conceptos abstractos, se ofrecen existencialmente a través de una historia, que además tiene un final feliz. El hagiógrafo provee a los cristianos de un modelo: un hombre como ellos. Llevado de una profunda inquietud religiosa, el protagonista inicia la búsqueda de la santidad. Sigue diferentes medios o pasos que le proporcionan una progresiva superación. Los milagros vienen a ratificar el éxito de su búsqueda (Baños Vallejo, La hagiografía como género, 133-134).

Ahora bien, Isabel Lozano-Renieblas ubica tres modos de desarrollo de las vidas de santos. El primero es el que denomina hagiografía de la conversión, que se caracteriza "porque el santo emprende la búsqueda de la verdad" ("El encuentro", 161), y sus momentos cruciales son la crisis y la resurrección. El segundo modo es el tipo biográfico en el que prevalece la "estética del encomio" ("El encuentro", 161), y en ella se encarece al santo en cuestión mediante la ponderación reiterada de sus milagros o sus sufrimientos. El último tipo es la hagiografía heroico-aventurera o novela hagiográfica. "Estos relatos se caracterizan porque operan con el tiempo de la aventura en un mundo regido por los valores de la fe" ("El encuentro", 162). En el caso de María Magdalena tenemos una vida previa licenciosa y pecadora, un momento de

1 Retomo cada una de las etapas que establece Fernando Baños Vallejo, La hagiografía como género, 138.

Medievalia 48, 2016, pp. 27-44 
conversión y posteriormente una vida dedicada a la prédica de la palabra de Dios en la que sucede un milagro que bien puede emparentarse con el suceso de una aventura protagonizada por dos esposos encomendados a la ayuda de María Magdalena. Llama la atención que la narración de la vida de la santa conservada en el Manuscrito escurialense comienza cuando Magdalena inicia su labor predicadora y milagrosa, y no se centra en la licenciosa vida anterior de la santa, la presenta así, no como una mujer pecadora que busca la redención, sino que enfatiza la presentación de la santa como una fémina digna de toda emulación y que posee el favor divino para ayudar a una familia aun en contra de las situaciones más adversas que se presenten en su viaje.

La historia de María Magdalena que contiene La leyenda dorada es considerablemente más amplia, comparada con la versión incompleta del 30 Manuscrito escurialense h-I-13, que comienza el relato cuando Magdalena, ya convertida, se dirige en compañía de otros a Marsella e inicia su labor evangelizadora con una pareja sobre la que obra su primer prodigio. Debido a que la mayor parte de la narración del relato del Manuscrito escurialense h-I-13 la ocupa la presencia de un único milagro, es importante definirlo brevemente. Los milagros son la prueba del vínculo con la divinidad por medio de lo sobrenatural y forman parte de las hagiografías. Se definen como "narraciones breves de los beneficios extraordinarios recibidos por algún individuo o alguna colectividad, en cuya consecución ha intervenido algún santo" (Montoya Martínez, apud Baños Vallejo, Las vidas de santos, 71) y son además un hecho "único e irrepetible, como una narración aparte dentro del relato primario". En ese sentido, es muy común que su autonomía sea casi absoluta y que "a veces el milagro se independice del relato que lo enmarca, aunque luego, como forma del relato breve que es, vuelva a insertarse como unidad menor en alguna narración extensa con propósito literario diverso" (Gómez Moreno, "La hagiografía", 275). Los milagros, como ya se señaló anteriormente, podían aparecer luego de la muerte del santo como prueba de gracia divina y, en otras ocasiones, acontecían durante la vida del biografiado: "Las narraciones de milagros podían aparecer a lo largo de las vitae de una santo siguiendo un esquema cronológico, o bien al final de la obra agrupados por similitud temática y complementando la vida" (García de la Borbolla, "El universo de lo maravilloso", 339). La función del milagro dentro de la historia de María Magdalena es el foco principal y el nudo argumental que pone en marcha la historia de los esposos y el cuidado de ellos por parte de la santa; posteriormente el centro de interés se desplaza hacia el viaje de los esposos a Roma. Hay que señalar que el milagro se encuentra dentro del género hagiográfico pero tiene una función distinta que en la ficción del roman: el 
milagro en la hagiografía "ofrece un marco más amplio, una perspectiva que viene dada por el contexto biográfico” (Baños Vallejo, La hagiografía como género, 132) donde se inscribe la pequeña historia y de esa manera los prodigios se inscriben en las dos finalidades de las vidas de santos: la alabanza y la ejemplaridad y, por otra parte, tiende a beneficiar a la figura del santo porque lo define como tal (Baños Vallejo, La hagiografía como género, 132133). Sin embargo, las características del milagro que contiene el Manuscrito escurialense $h-I-13$, se asemejan al milagro ficcional, desligado por completo del marco biográfico, como señala Fernando Baños Vallejo: "el milagro literario carece del contexto biográfico: importan sobre todo las circunstancias que destacan el prodigio como la salvación, de las cuales la más peculiar es que el milagro se produzca in extremis" (La hagiografía como género, 133), es decir, en una situación llevada hasta sus últimas consecuencias, como efectivamente sucede en el milagro que se presenta aquí, el cual puede leerse como una pequeña aventura que involucra peligro, con el respaldo sobrenatural de santa María Magdalena.

El milagro de santa María Magdalena, presente tanto en la narración de La leyenda dorada como en el relato del Manuscrito escurialense h-I-13, relata la aventura de un matrimonio pagano de Marsella que desea un hijo y cuando la mujer está encinta — por intercesión de Magdalena_, la pareja planea viajar a Roma para constatar las maravillas que les contó la santa, conocer a San Pedro y convertirse al cristianismo. En el viaje de la pareja por mar, sobreviene una tormenta, el parto se adelanta, la mujer muere y la criatura es abandonada junto al cuerpo de su madre en un lugar pedregoso. Cuando el desgraciado marido llega solo y viudo a Roma se entera - junto con el lector- que la esposa y el hijo que creía muertos viven y que Magdalena los cuidó todo el tiempo que duró su peregrinaje.

La disposición del texto en cada una de las versiones ya apunta ciertas diferencias significativas en la concepción de la historia y su finalidad. La narración de María Magdalena en La leyenda dorada no presenta ninguna segmentación mientras que la edición del Manuscrito escurialense h-I-13 divide la historia en partes bien diferenciadas: ${ }^{2}$ la primera, intitulada "De santa

2 Respecto a las subdivisiones, no hacen ninguna referencia Maier y Spaccarelli en el estudio codicológico de su artículo; por otra parte, Carina Zubillaga, en la descripción del manuscrito de su edición crítica, se refiere a las iniciales que marcan el comienzo de las historias del Escurialense y de las rúbricas que separan los capítulos y los dibujos de máscaras dobles que aparecen al principio de algunos relatos, pero no detalla los subtítulos presentes en ninguno de los relatos, ni añade ninguna nota al pie en el texto crítico. Véase Maier y Spaccarelli, “Ms. Escurialense h-I-13”, XX, XXI.

Medievalia 48, 2016, pp. 27-44 
María Magdalena”, la segunda comienza de inmediato con la inserción de la historia del matrimonio que carece de nombres propios, "Milagro que fizo santa María Magdalena”, la tercera refiere las distintas etapas del milagro y desde entonces se aprecia la focalización de la voz narrativa hacia la esposa del matrimonio. Hay que hacer notar las distintas maneras de llamar al esposo en los apartados que siguen: "Cómo se fue la mujer del caballero con él", "Cómo parió la dueña", "Cómo mamava el niño seyendo su madre muerta" y finalmente una pequeña parte de "Cómo el romero ${ }^{3}$ falló el niño trebejando ribera de la mar", hasta que se interrumpe el texto por la mutilación del original. Estas características apuntan hacia dos sistemas textuales distintos. El texto que carece de los subtítulos pertenece a la estructura canónica de la hagiografía y su continuo totalizador, en tanto que las partes con una segmentación episódica recuerdan el tratamiento de los libros para clases dirigentes, concebidos para su meditación y reflexión acerca de ciertos temas específicos. Sobre todo en el siglo XIII se dio importancia a la transmisión del saber. Dividir los contenidos de una narración favorece la amplificatio sin dañar la estructura básica de la historia y permite al lector enfocarse en ciertos pasajes reveladores y así leerlos una y otra vez, multiplicando su posibilidad de deleite y provecho.

En el análisis comparativo es importante distinguir el discurso indirecto del directo. En La leyenda dorada hay un predominio del discurso directo, si bien es menos afectivo que en el Manuscrito escurialense h-I-13 donde la participación del narrador, su guía y sus encarecimientos emocionales - muy cercanos a la peroratio - son cada vez más relevantes a medida que avanza el relato. También hay que notar que en ambas versiones los esposos no tienen nombres propios. Se detallan a continuación los cambios entre los dos textos:

1.- María Magdalena llega a Marsella en una embarcación. Comienza su labor evangelizadora.

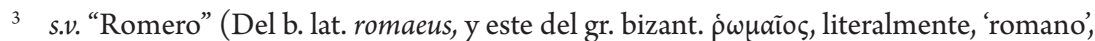
nombre que se aplicaba en el Imperio de Oriente a los occidentales que lo cruzaban en peregrinación a Tierra Santa y, en fecha posterior, a los peregrinos de Santiago y de Roma).1. adj. Dicho de un peregrino: Que va en romería con bordón y esclavina. U. m. c. s. Diccionario de la Real Academia Española. 


\begin{tabular}{|c|c|}
\hline La leyenda dorada & Manuscrito escurialense h-I-13 \\
\hline $\begin{array}{l}14 \text { años después de la Resurrec- } \\
\text { ción de Jesús, los infieles obli- } \\
\text { gan a Maximino, a Magdalena, } \\
\text { Lázaro, Martha, Martila, San } \\
\text { Cedonio y otros a embarcarse, } \\
\text { y los abandonan en mar abierto } \\
\text { para que mueran. Dios los lleva } \\
\text { a Marsella. Nadie les da asilo, así } \\
\text { que se refugian en la techumbre } \\
\text { de un templo pagano. Magdale- } \\
\text { na predica, es bella y convincen- } \\
\text { te. Los que la escuchan no saben } \\
\text { que alabar más: si su belleza o su } \\
\text { elocuencia. }\end{array}$ & $\begin{array}{l}\text { No hallaron quién les diera albergue y se que- } \\
\text { daron a la ribera, yacieron en las piedras e } \\
\text { hicieron plegarias y oraciones toda la noche. } \\
\text { Magdalena predica, es bella y elocuente y deja } \\
\text { maravillados a todos los que la escuchan. }\end{array}$ \\
\hline
\end{tabular}

Santiago de la Vorágine recalca el ambiente de odio y persecución contra los primeros cristianos, quienes son unos mártires abandonados en el mar, en tanto que el manuscrito resalta la decisión de evangelizar de Magdalena y sus allegados quienes se arriesgan a llevar la palabra de Dios a tierras lejanas y se abandonan a la voluntad divina del "buen viento". Otra divergencia entre las versiones es el cambio del santuario hereje del texto canónico por una ribera pedregosa en la historia del manuscrito. En cuanto al espacio que enmarca las acciones, el templo de la idolatría pagana es un lugar propicio para guarecerse y para predicar, en tanto que la ribera y sus asperezas caracterizan la fortaleza ascética de Magdalena y sus seguidores, quienes incluso velan toda la noche por alabar a Dios. Claramente en esta contraposición se aprecia un encarecimiento de la voluntad del personaje principal por encima de las circunstancias, mismas que victimizan a María Magdalena y sus seguidores en la versión de Vorágine. Se percibe en el texto del Escurialense una preferencia por encomiar valores mundanos, aunque dentro del contexto religioso. María Magdalena es una líder bella y admirable que elige quedarse entre las piedras para predicar, es decir, conscientemente elige el ambiente más difícil para demostrar que es capaz de sobreponerse a él. Así, se puede observar que el escritor del Escurialense está buscando la exaltación de un personaje femenino a través de elementos hagiográficos, pero está arraigándolos en un ambiente y actitudes mundanas, a diferencia del texto de Vorágine que reiteradamente señala la voluntad de Dios, busca la atmósfera de persecución y martirio, y le interesa una precisión temporal exacta. 
2.- Primer milagro. Aparece el gobernador y su esposa. La situación precaria de los cristianos.

\begin{tabular}{|c|c|}
\hline La leyenda dorada & Manuscrito escurialense h-I-13 \\
\hline $\begin{array}{l}\text { Llega al templo el gobernador de } \\
\text { la provincia con su esposa e hijos } \\
\text { para ofrecer sacrificios en honor } \\
\text { de los ídolos. Magdalena los di- } \\
\text { suade. }\end{array}$ & $\begin{array}{l}\text { "Milagro que fizo Santa María Magdalena" Un } \\
\text { "señor de toda aquella provincia” llega a aquel } \\
\text { lugar para hacer sacrificios a los ídolos. No te- } \\
\text { nía hijos y deseaba tener uno. } \\
\text { Magdalena lo disuade. } \\
\text { El narrador detalla en qué consiste la doctrina } \\
\text { de Cristo que predicaba Magdalena. Recalca } \\
\text { además que era hermosa y tenía otros segui- } \\
\text { dores. } \\
\text { Posteriormente, la mujer del señor, por medio } \\
\text { de sus criados, envía alimentos en secreto a los } \\
\text { cristianos porque se recela de la crueldad de su } \\
\text { esposo y de dos desleales que vivían con él. }\end{array}$ \\
\hline
\end{tabular}

Aquí aparecen cambios significativos que añaden dramatismo, actualidad y suspenso a la escena del cuadro. El Manuscrito escurialense h-I-13 cambia la imagen de un gobernador por la de un acaudalado señor feudal cuya falta de descendencia vuelve desesperada su condición, a diferencia de la situación del primer texto en la que ya tiene vástagos y se acerca solamente a ofrecer un obsequio a sus dioses. La caracterización del esposo como un señor feudal supone un acercamiento a los posibles lectores del Escurialense señalando, por medio de una actualización, la vigencia de lo que sucede en los tiempos de los primeros cristianos en la Edad Media. La bondadosa mujer del señor manda - por iniciativa propia - alimentos a los cristianos que están sufriendo a la intemperie en el pedregal de la ribera del río, conmovida por la pobreza y estrecheces de los católicos. Efectivamente, la rica y compasiva señora guardaba simpatía por María Magdalena y sus seguidores. Sin embargo, ella tiene miedo de su esposo y se revela otro nudo de interés para el lector que eclipsa la historia principal: un marido cruel y un peligro inminente. Hay un mayor desarrollo en la versión del Manuscrito escurialense $h-I-13$, una clara amplificatio hacia elementos significativos para las receptoras del texto. Estructuralmente se confirma la apreciación de Carina Zubillaga en el prólogo a su edición del Manuscrito escurialense h-I-13, cuando apunta que hay una "preeminencia femenina como la principal característica unitaria de la colección $[\ldots]$ existe un particular interés del compilador del códice en el 
tema de la santidad y la virtud femenina" (Zubillaga, "Estudio preliminar", XXXII). Y, sobre todo, el interés por estimular la ejemplaridad de las mujeres a partir de los valores católicos a través de una transición desde la hagiografía hasta el roman, como notaron Maier y Spacarelli: "There is a progression in the ms away from the religious saints' lives to the more secular romances" (Maier y Spaccarelli, "Ms. Escurialense h-I-13”, 21). Zubillaga incluso apuntó la posibilidad de que el manuscrito tuviera una receptora laica específica: María de Molina (1264-1321), reina madre quien se ocupó de la crianza y custodia de Fernando IV hasta que éste tuvo edad suficiente para reinar y quien se enfrentó a una nobleza desleal y levantisca (Zubillaga, "Estudio preliminar", XXXIV-XXXV). Mediante este tipo de textos se creaba la posibilidad de alentar a una mujer sola con importantes responsabilidades por medio de la creación de personajes dignos de emulación en situaciones mundanas adversas, en las que la mujer debía ser operativa y no meramente pasiva.

Se aprecia aquí el primer motivo de la historia del milagro de los esposos: la esterilidad de la mujer y la búsqueda de un vástago, que no ha sido concedido a la pareja, tal como lo presenta el Escurialense. Este motivo es muy conocido en la tradición literaria y en el cuento tradicional, y ya en el periodo medieval:

La estrecha relación entre la generación y el pensamiento religioso pertenece a los estratos más antiguos de la tradición. El motivo contó, además, con el prestigio que le otorgaba el modelo veterotestamentario, donde la esterilidad era expresión del castigo y de la ira divina $[\ldots]$ los hijos nacidos en estas circunstancias tendrían un destino señalado, pues su concepción habría sido el resultado de una alianza entre materia y espíritu despojada del pecado de concupiscencia, una consecuencia de la voluntad divina más que del acoplamiento de los padres. De ahí que en la hagiografía el motivo formara parte de su paradigma estructural (Luna Mariscal, "De la mujer infecunda”).

En el caso del milagro, el motivo de la esterilidad de la mujer añade dramatismo y patetismo a la búsqueda de la pareja y funciona dentro de la historia para perfilar a otro personaje femenino que representa un modelo de comportamiento de la mujer virtuosa: la esposa del matrimonio. Esta mujer que se halla en la necesidad de tener un vástago es caritativa y generosa. Y el relato del Escurialense añade dos núcleos de intriga y de adversidad con los que la esposa tiene que lidiar, además del motivo de la esterilidad: un marido cruel y la sospecha de que dos criados quieren dañar a su esposo. Sin duda, un entorno complejo en el que sólo una mujer fuerte y bendecida por Dios puede salir adelante. 
3.- Apariciones nocturnas de Magdalena a la mujer y luego a ambos esposos. Ayuda del matrimonio a los cristianos y concepción milagrosa del hijo.

\begin{tabular}{|c|c|}
\hline La leyenda dorada & Manuscrito escurialense h-I-13 \\
\hline $\begin{array}{l}\text { La mujer despierta asustada y le habla al } \\
\text { esposo, también impresionado. Los dos } \\
\text { hablan y por un discurso directo, la mu- } \\
\text { jer propone ayudar a los cristianos para } \\
\text { no indignar "al Dios ése del que hablan". } \\
\text { A la mañana siguiente les dan albergue y } \\
\text { todo cuanto necesitan. } \\
\text { El gobernador pregunta a María Mag- } \\
\text { dalena si lo que predica es verdad. Ella } \\
\text { ratifica la autoridad de Pedro en Roma } \\
\text { "él garantizó con milagros la verdad de lo } \\
\text { que [ella] enseña". } \\
\text { El esposo promete a María Magdalena } \\
\text { que ambos se convertirán al cristianismo } \\
\text { si Dios les concede un hijo. Ella acepta, } \\
\text { pide a Dios por ellos y al poco tiempo, la } \\
\text { muier aueda preñada. }\end{array}$ & $\begin{array}{l}\text { Magdalena se aparece en sueños a la } \\
\text { esposa del señor. Su diálogo aparece } \\
\text { en un discurso indirecto. La mujer no } \\
\text { dice nada al día siguiente. En la segun- } \\
\text { da noche nuevamente la santa repren- } \\
\text { de a la mujer, otra vez con discurso } \\
\text { indirecto. Tampoco esta vez la esposa } \\
\text { dice algo a su marido. } \\
\text { La tercera noche Magdalena se les } \\
\text { aparece a los dos esposos. Está furiosa } \\
\text { y de su rostro parecía que salía fuego } \\
\text { "o así como si la casa ardiese". Median- } \\
\text { te un discurso directo le reprocha al } \\
\text { señor. Lo llama cruel por vivir con lu- } \\
\text { jos mientras aquellos mueren de ham- } \\
\text { bre. No amenaza con la ira de Dios. } \\
\text { Cuando ambos esposos despiertan, } \\
\text { la mujer dice que deben obedecer a la } \\
\text { bendita María Magdalena y advierte a } \\
\text { su esposo sobre el castigo de Dios que } \\
\text { podría sobrevenirles. Dice a su esposo } \\
\text { que ambos le pidan a Magdalena que } \\
\text { ruegue a Dios para que puedan con- } \\
\text { cebir. El señor hace caso del consejo } \\
\text { de su mujer y les da posada "e lo que } \\
\text { les fuese menester". }\end{array}$ \\
\hline
\end{tabular}


Este segmento es muy revelador. Las apariciones de Magdalena a la pareja son un motivo de reiteración que remarca el paso del tiempo en ambas narraciones. La furia de la santa, comparada con el fuego que consume la casa entera, le añade dramatismo a la versión del Manuscrito escurialense $h-I-13$, además, esa misma versión minimiza el papel del señor y resalta el de su esposa como mediadora y portavoz de lo que debe hacerse. El Manuscrito escurialense h-I-13 no refiere el maltrato y los insultos de la santa al hombre, tampoco las preguntas inquisitivas de éste a Magdalena, ni la refrendada autoridad papal en materia católica. Así, se comprueba que al escritor del Escurialense no le interesa hacer una caracterización estridente de sus personajes femeninos. Está más interesado en crear modelos de comportamiento a través de los cuales se constate cómo las mujeres hacen frente a un entorno conflictivo. El Escurialense traslada las acciones y palabras que, en La leyenda dorada pertenecían a María Magdalena y al esposo para ponerlas en voz de la esposa: ella calla y omite las apariciones de Magdalena por miedo a su marido, no por negligencia. Esta vez, Magdalena llama al hombre "cruel" y de esta forma se verifica el dicho y los temores de la esposa, virtuosa a pesar de las adversidades.

Se destaca en la versión del Escurialense que quien propone y organiza las acciones sensatas en el relato es la esposa: la mujer actúa como toda una creyente, aconseja a su marido, éste le cree ciegamente y es ella misma quien amenaza con el castigo divino; hay en esta versión una elaboración ficcional y literaria más elaborada, que enfoca y subraya la pugna de los desacuerdos humanos por sobre el desarrollo y la trascendencia de los asuntos divinos. ${ }^{4}$ Finalmente, en la interpretación del manuscrito, quien propone pedirle a Magdalena que abogue por la pareja para concebir es la esposa, no el marido, como sucede en la versión de Vorágine. Hay, pues, una reelaboración de los discursos y cambios en la construcción que favorecen las acciones y elecciones de la esposa en detrimento de las decisiones del marido. Estas alteraciones no afectan la estructura general del milagro, no obstante, sirven para ilustrar la conducta de una mujer prudente. La promesa del esposo encaminada hacia la conversión del matrimonio contenida en La leyenda dorada es irrelevante de acuerdo con lo que ocurre en el Manuscrito escurialense h-I-13: las cristianas y diligentes acciones de la esposa han dejado al esposo tan sólo con autoridad

4 Aunque con las salvedades del caso, este alejamiento paulatino de los valores religiosos y un encauzamiento hacia lo humano es una característica importante de la novela para Carlos García Gual: "reducción a lo psicológico y a lo puramente humano, cuando la medida de lo humano es el hombre común [...]" ("Aparición de la novela como género literario", Los orígenes de la novela, 32).

Medievalia 48, 2016, pp. 27-44 
aparente para decidir la conversión de los dos. La cristianización de la esposa ya está implícita en las acciones de la mujer, según se infiere en el relato. Así, en el Escurialense, el marido es guiado sabiamente por ambas mujeres, la santa y la esposa. Este cambio, en la focalización y en las acciones de los personajes, reditúa sobre todo en el personaje de la esposa, que sabe distribuir las prioridades y desenvolverse en un entorno difícil.

4.- Viaje del gobernador a Roma. Tormenta, parto y muerte de la mujer.

\begin{tabular}{|c|c|}
\hline & Manuscrito escurialense h-I-13 \\
\hline $\begin{array}{l}\text { La mujer insiste y llora, se arrojó sollo- } \\
\text { zando a los pies de su esposo y no se } \\
\text { levantó hasta que "hizo lo que quiso". } \\
\text { Cuando se embarcan los esposos, Ma- } \\
\text { ría Magdalena les pinta en los hombros } \\
\text { unas cruces para que Dios los proteja } \\
\text { del Demonio en la travesía. } \\
\text { Luego subieron los esposos a la nave } \\
\text { bien provista. Encargaron a la santa sus } \\
\text { haberes en su ausencia. } \\
\text { Pasó un día y una noche y comenzó una } \\
\text { tempestad. Hubo olas y viento enfureci- } \\
\text { dos. La esposa tuvo miedo y mareos, se } \\
\text { le adelantó el parto con violentas con- } \\
\text { vulsiones y fuertes dolores, nada más } \\
\text { parió, le sobrevino la muerte. Aquí vie- } \\
\text { ne una larga queja por parte del narra- } \\
\text { dor y un emotivo lamento en discurso } \\
\text { directo del gobernador. }\end{array}$ & $\begin{array}{l}\text { "Cómo se fue la mugier del caballero } \\
\text { con él” } \\
\text { Quiso ver el señor si lo que decía Mag- } \\
\text { dalena era verdad. Cuando la mujer lo } \\
\text { supo, quiso ir con él. El esposo no quie- } \\
\text { re que ella vaya por su avanzado emba- } \\
\text { razo, él desea que ella se quede en casa } \\
\text { y "endereçades vuestras cosas", los ca- } \\
\text { minos son malos y el mar es peligroso. } \\
\text { La mujer no dice nada, pero llora y se } \\
\text { lanza a los pies de su esposo hasta que } \\
\text { él le permite ir. } \\
\text { Le encargan sus propiedades a Magdale- } \\
\text { na, quien pone la señal de la cruz en sus } \\
\text { espaldas y les dice que por San Pedro po- } \\
\text { drían comprobar todo lo que ella les dijo. } \\
\text { "Cómo parió la dueña" } \\
\text { Pasó un día y una noche y comenzó una } \\
\text { tempestad y todos se asustaron y la mu- } \\
\text { jer parió al niño. } \\
\text { El narrador hace una dramática pon- } \\
\text { deración del sufrimiento y de cómo } \\
\text { el bebé "buscaba la teta" de su madre } \\
\text { muerta. }\end{array}$ \\
\hline
\end{tabular}


En este segmento narrativo se notan diferencias en la caracterización de los personajes: en el Manuscrito escurialense h-I-13, el señor de la provincia ahora es un "cavallero"; hay un desplazamiento temporal importante para acercar el texto a sus receptores inmediatos; también se nota el marco de una atmósfera suntuaria y caballeresca, de esta manera se ubica un entorno refinado y apetecible. Es notorio aquí el traslado de un ambiente de santidad y persecución hagiográfica hacia un ámbito cortesano que explora en la hagiografía pautas de conducta para llevarlas a un entorno secular, como demostró Margaret Hurley en un interesante artículo, "the courtly romance functioned primarily as a vehicle for the exploration of the new secular ideals of the courtly society" ("Saints' Legends", 60). Se aprecia además el contraste de las actitudes de una esposa ordinaria en La leyenda dorada y otra mujer muy distinta conforme a los valores cristianos en el Escurialense, pues, ante la negativa del cónyuge, la versión de Vorágine presenta a una mujer caprichosa que insiste y se sale con la suya; la del Escurialense, por el contrario, descubre a una mujer sufrida y silenciosa, cuya sinceridad provoca el cambio en la decisión del marido. En esta parte se aprecia la intromisión paulatina de la ficción caballeresca en el discurso hagiográfico. Esto tiene importantes repercusiones en las finalidades de cada uno de los textos: la hagiografía centra su foco de interés en la santa y su intercesión, y el roman se dedica a destacar elementos propios de la novela, como el viaje y sus vicisitudes, cierta tendencia a centrarse en la pareja desde un punto de vista amoroso, ${ }^{5}$ cuyo centro de interés son los altibajos que, al fin, serán superados, para que la feliz familia se reencuentre, y una más compleja construcción de personajes, especialmente el femenino encarnado en la esposa.

Una vez más, las palabras dolorosas del gobernador en La leyenda dorada son trasladadas al narrador, quien tendrá una participación más activa en el relato del Manuscrito escurialense h-I-13 a partir de este momento. La construcción ficcional del narrador es compleja y fluctuante en el Manuscrito escurialense $h-I-13$, pues esta voz que cuenta la historia dirige su interpretación a partir de pautas que al principio de la historia pertenecieron al discurso religioso, pero conforme avanza la narración, las recreaciones del narrador tienen acentos cada vez más literarios, emocionales y dramáticos que insertan al lector en un universo textual lleno de matices sentimentales.

Estas distintas funciones de las que se allega el narrador (ora como testigo, ora en digresiones y encarecimientos), lo construyen de una manera más compleja. Se trata de un narrador más involucrado con lo que escribe, que ordena,

5 Ana Baquero Escudero distingue el viaje y el amor como elementos fundamentales de la novela griega ("La novela griega: proyección de un género en la narrativa española", 22).

Medievalia 48, 2016, pp. 27-44 
crea suspenso, construye verosimilitud, da emotividad, encarece, se sorprende y aconseja; y visto así, puede ser el personaje mejor construido de todo el relato.

5.- Tentativa de los marineros de arrojar el cuerpo de la esposa por la borda. Arribo a tierra y abandono del cuerpo de la mujer y el recién nacido.

\begin{tabular}{|c|c|}
\hline La leyenda dorada & Manuscrito escurialense h-I-13 \\
\hline $\begin{array}{l}\text { Los otros tripulantes de la } \\
\text { nave (discurso directo) quie- } \\
\text { ren arrojar el cadáver al mar. } \\
\text { El gobernador les suplica que } \\
\text { no lo hagan, por compasión } \\
\text { de su hijo "que busca la teta" } \\
\text { y que, por piedad, esperen. } \\
\text { A lo lejos, ven una colina pe- } \\
\text { ñascosa y como no puede en- } \\
\text { terrar a la mujer, el gobernador } \\
\text { deja en una cueva el cuerpo } \\
\text { de su mujer y al bebé sobre su } \\
\text { capa y en discurso directo re- } \\
\text { clama abundante y lastimosa- } \\
\text { mente a María Magdalena, le } \\
\text { ruega amparo y misericordia } \\
\text { para su mujer e hijo. }\end{array}$ & $\begin{array}{l}\text { Los tripulantes de la nave quieren arrojar el cadá- } \\
\text { ver al mar, esto lo dice el narrador. "Et sabed que } \\
\text { esto es verdat e cosa bien provada que la mar non } \\
\text { quer en sí cosa muerta". } \\
\text { El romero les pide (en discurso directo) que espe- } \\
\text { ren un poco por compasión de su hijo. } \\
\text { "Cómo mamava el niño seyendo su madre muerta". } \\
\text { A lo lejos ven una montaña y el romero pensó de- } \\
\text { jar ahí el cuerpo de la madre y al niño. } \\
\text { Entonces les dice a los tripulantes que tomen lo } \\
\text { que quisieran de su haber y "ponedme a la dueña } \\
\text { e el niño en aquella montaña". El suelo estaba pe- } \\
\text { dregoso, el hombre no puede enterrar a su mujer. } \\
\text { Se los lleva a un lugar apartado en la sierra y pone } \\
\text { ahí al niño, prendido a las tetas. El viudo reclama } \\
\text { a María Magdalena en discurso directo y luego } \\
\text { coloca su capa encima de su mujer e hijo. } \\
\text { Siguen exclamaciones y ponderaciones del narra- } \\
\text { dor. Según él, Magdalena cuidó personalmente a } \\
\text { madre e hijo. Predicó y cuidó al mismo tiempo. } \\
\text { Era maestra y ama, eso lo encarece el narrador. } \\
\text { Al mismo tiempo que recalca, adelanta sucesos: } \\
\text { gracias a la santa, el alma de la mujer presenció } \\
\text { todo: estuvo con su esposo en la romería Roma- } \\
\text { na. ¡Magdalena hizo que en un vaso=cuerpo vacío } \\
\text { hubiera leche! "Et sabet que así son guardadas las } \\
\text { cosas que son encomendadas a María Magdalena". }\end{array}$ \\
\hline
\end{tabular}


Como se puede ver, el esposo tiene una condición estamental distinta en ambas versiones de la historia. En La leyenda dorada, es un gobernador de la época del primer cristianismo que personalmente lleva el cuerpo de su mujer y su hijo a la cueva; en el Manuscrito escurialense h-I-13, es un rico señor-caballero y noble que ofrece generosamente sus riquezas a los tripulantes para que lleven el cuerpo de su esposa a donde él pueda enterrarlo. De esta manera, en la historia del Escurialense los navegantes no tienen caridad — una de las virtudes teologales del cristianismo-, sino interés, pues el esposo les paga. Se aprecia aquí una importante secularización de los motivos que mueven a los personajes, en vista de que ya no son valores religiosos, sino los monetarios los que mueven el interés.

Por otra parte, la preferencia por los tratamientos sentimentales se justifica desde un punto de vista del emisor y las lectoras a las que el libro iba dirigido: el público femenino prefiere la afectividad encarecida. Vemos así la conformación de un personaje masculino noble, caballero y acaudalado, acorde con los gustos del público, para el que se perfila un personaje poderoso, adinerado y seductor, que también funciona como modelo de comportamiento atractivo para los lectores varones del Manuscrito escurialense. Así se ve, por ejemplo, en las palabras del esposo cuando deja a su esposa muerta y a su hijo recién nacido, prendido del seno del cadáver:

¡Ay, santa María Madalena — dixo él! ¿E por qué veniste tú nunca al puerto de Marsella? Por mi destroimiento e por mi desterramiento veniste tú. E yo, cativo, ¿por qué te crey de començar esto? ¿Rogaste tú por esto tu Dios que mi mujer conçebiese, por se perder lo que traxiese? Ora son perdidos anbos, el conçebido e la que conçebió; ca la madre es muerta con las coitas e con los dolores que sufrió, e el niño nasçió por morir, que non ha quien lo críe. Es esto es lo que yo gané por tu ruego, a que encomendé todas mis cosas. Yo te demando e ruego que ruegues a tu Dios que, sy Él es tan poderoso como tú pedricas, que aya merçet de la alma d'esta dueña, e que por tu ruego aya piadat de aquesta niño, que se non pierda ("De santa María Madalena”, 14).

También destaca en este cuadro la presencia cada vez más fuerte del narrador, quien no sólo ordena el relato y lo estructura para despertar el interés en el lector, sino que además interviene directamente en el texto y, como otras veces, aporta el patetismo y la emocionalidad predominantes en el texto. Así, por ejemplo, luego de que el esposo deje a su mujer e hijo y entre en la nave con los marineros, el narrador encarece a la santa a la que el esposo había desafiado: 
¡Ay, qué misericordia de Jhesu Christo!¡Ay qué meresçimiento de la Madalena!;Ay, qué bendita partera ella escogió!, que fue pedricar en tierra, e le dio conforte e ayuda al romero, que por su conforte non se desesperase, e ella lo confortó que non fallesçiese por su llorar. Ella estudo al parto de la madre, ella fizo el ofiçio de la maestra, ella confortó la dueña en sus dolores. Ella confortó el niño que llorava, ella fizo el ofiçio de ama, ella le dio la leche.jQuién oyó nunca estas cosas! Ella enseñava e pedricava en tierra, e la consejava en mar. Ella era maestra; ella era ama; ella confortava el romero, que non dexase lo que començara; ella criava el niño que llorava por lo confortar e lo quitar de llorar (“De santa María Madalena”, 14-15).

\section{6.- Llegada del gobernador a Roma y su encuentro con San Pedro.}

\begin{tabular}{|c|l|}
\hline La leyenda dorada & \multicolumn{1}{|c|}{ Manuscrito escurialense h-I-13 } \\
\hline $\begin{array}{l}\text { El gobernador llegó a Roma y trató } \\
\text { de localizar a San Pedro. Cuando }\end{array}$ & "Cómo el romero falló el niño trebejando \\
éste lo vio de lejos con la cruz le & El narrador regresa al romero "ora tornare- \\
preguntó de dónde era. Y el gober- & mos a nuestro romero e non hayades enojo \\
nador le contó al papa todo lo que & de oír el conforte que ella le dio de su des- \\
había sucedido. & conforte” La nave llegó a Roma y cuando \\
& San Pedro vio al "cruzado" yle preguntó por \\
& dónde había venido, el papa supo todo. Y el \\
& romero le contó toda su historia. \\
\hline
\end{tabular}

La interrupción del segundo relato impide analizar a detalle el resto del milagro, pero en esta pequeña parte se puede ver la anticipación de la historia por el subtítulo y por el narrador, que adelanta sucesos y crea suspenso para interesar al lector y, al mismo tiempo, estructurar la historia.

Aunque el Manuscrito escurialense h-I-13 presenta la historia de María Magdalena incompleta, es una narración reveladora que evidencia los pequeños cambios paulatinos por donde la ficción se filtra en la hagiografía, representada en este trabajo por la versión de Santiago de la Vorágine. Se apreció en el análisis la segmentación que fomentó la amplificatio con una intención de construcción literaria y un incremento en el aspecto sentimental. Por otra parte, se notó la construcción de personajes moldeados por dos componentes: la atmósfera caballeresca de los textos de aquella época y los gustos femeninos de expresión emocional. A pesar de las evidentes analogías entre hagiografía y roman, hay una gran diferencia entre lo que uno y otro género intentaron 
transmitir. El sustrato de la hagiografía, como texto que promociona los valores católicos sigue operando en el texto del Manuscrito escurialense h-I-13, pero con un sesgo distinto, ya que en el texto hagiográfico lo más importante sigue siendo la salvación de las almas de la pareja, viajar a Roma para volverse católicos los dos y la intercesión de la Santa cuando todo se creía perdido. En el caso del roman escurialense, lo que importa es el tiempo presente, y enseñar a las mujeres mediante personajes femeninos el modo de resolver dificultades y sobrellevar relaciones sociales en un mundo conflictivo. También presenta la estilización estamental de la corte, pues de acuerdo con la posición del esposo, la acción se desenvuelve en un entorno cortesano. El texto del Manuscrito escurialense $h-I-13$ encarece los avatares de una mujer fortalecida por Dios ante la adversidad y los incidentes de su vida matrimonial. Hay que destacar que, desde luego, la figura de María Magdalena aparece eclipsada por la vida de una pareja cuyo periplo, aunque de índole religiosa, recuerda aspectos esenciales de la novela de aventuras como el viaje, las vicisitudes amorosas, la separación y el reencuentro final. El orden del Manuscrito escurialense va gradualmente de la hagiografía al roman, pero como ya se ha visto en este trabajo, aún en su primera historia, el Escurialense presenta cambios significativos en esa transición.

\section{BIBLIOGRAFÍA}

Baños Vallejo, Fernando, La hagiografía como género literario en la Edad Media: tipología de doce vidas individuales castellanas, Oviedo: Universidad de Oviedo, 1989.

Baños Vallejo, Fernando, Las vidas de santos en la literatura medieval española, Madrid: Laberinto, 2003.

BAQUERo EsCUdERo, ANA, "La novela griega: proyección de un género en la narrativa española”, RILCE, 1, 1990, 19-45.

García de la Borbolla, Ángeles, "El universo de lo maravilloso en la hagiografía castellana", Boletín de la Real Academia de Buenas Letras de Barcelona, 47, 1999-2000, 335-351.

García GuAL, Carlos, “Aparición de la novela como género literario”, en Los orígenes de la novela, Madrid: Istmo, 23-63.

Gómez Moreno, ÁNGEL, “La hagiografía, clave poética para la ficción literaria entre medievo y barroco con no poco apuntes cervantinos”, Edad de Oro, 23, 2004, 249-278.

Hurley, Margaret, “Saints' Legends and Romance Again: Secularization of Structure and Motif”, Genre, 8, 1975, 60-75. 
LOZANO-RENIEBLAS, ISABEL, "El encuentro entre aventura y hagiografía en la literatura medieval”, Actas del XIII Congreso de la Asociación Internacional de Hispanistas 1998, Madrid: Castalia, 2000, 161-167.

Luna Mariscal, Karla Xiomara, "De la mujer infecunda a la madre del héroe. El motivo de la dificultad en la concepción en algunas historias caballerescas breves”, Atalaya, 12, 2011, sin paginación. En línea: http://atalaya.revues. org $/ 733$.

Maier, John R. y Thomas D. Spaccarelli, "Ms. Escurialense h-I-13: Approaches to a medieval anthology”, La Corónica, II, 1982, 18-34.

Real Academia Española, Diccionario de la lengua española, Madrid: Espasa, 2015.

SAntiago de la Vorágine, La leyenda dorada, trad. de Fray José Manuel Macías, Madrid: Alianza, 2011.

44 Zubillaga, Carina, Antología castellana de relatos medievales (Ms.Esc.h-I-13), Buenos Aires: Seminario de Edición y Crítica Textual, 2008. 